\title{
Gas liquid chromatography in the rapid diagnosis of meningitis
}

\author{
I. R. FERGUSON ${ }^{1}$ AND P. V. TEARLE
}

From the Public Health Laboratory, Luton and Dunstable Hospital, Lewsey Road, Luton LU4 ODZ, UK

SUMMARY Gas liquid chromatography was employed to detect lactic acid in the cerebrospinal fluid of patients suspected of having bacterial meningitis. The technique was found to be both rapid and reliable. Differentiation between aseptic, purulent, and partially treated bacterial meningitis was readily achieved. The effectiveness of therapy in bacterial meningitis was indicated by a rapid fall in the concentration of lactic acid.

In the clinical laboratory the rapid diagnosis of pyogenic meningitis is of paramount importance if the clinician is to institute appropriate therapy and negate the possible development of serious sequelae. Often, previously administered antimicrobial agents decrease the incidence of positive findings in the initial diagnostic lumbar puncture fluid and may result in delayed diagnosis. A further difficulty is that neither the laboratory examination of cerebrospinal fluid (CSF) nor the clinical findings may distinguish clearly viral from bacterial meningitis. Indeed, in patients with viral meningitis the CSF findings occasionally suggest a bacterial cause because of a low glucose concentration, elevated protein concentration, and a predominantly polymorphonuclear leucocyte response. During the last decade the introduction of several rapid tests has aided in the diagnosis of meningitis. These include detection of endotoxins and of specific bacterial polysaccharide antigens. Endotoxins are produced by Gramnegative organisms multiplying in the CSF, and are readily detected by the limulus test, which is both rapid and specific. The main limitation of this test is the negative results given by Gram-positive bacteria. Counter-current immunoelectrophoresis, which may be used to measure polysaccharide antigens in CSF and serum, has a success rate varying from $70 \%$ to $90 \%$ in the diagnosis of bacterial meningitis due to Neisseria meningitidis, Haemophilus influenzae, Escherichia coli, and Streptococcus pneumoniae (Lancet, 1976). Greenwood et al. ${ }^{1}$ Present address: Public Health Laboratory, County
Hospital, Hereford HR1 2ER, UK

Received for publication 8 June 1977
(1971) reported that counter current immunoelectrophoretic examination was superior to the conventional bacteriological methods of culture and Gram-staining.

Polysaccharide antigens may also be detected by means of latex particles coated with antibodies, but, as with immunoelectrophoresis, the success of the investigation depends on the quality of the commerically available antisera and to date some antisera have been disappointing. Group B meningococcal polysaccharide antisera have proved extremely difficult in this respect, so that false negative results relating to this organism are not unusual (Jones and Abbott, 1976).

Sixty years ago Levison (1917) suggested that the changes in CSF pH in pyogenic meningitis were due to fluctuations in the concentration of lactic acid. This finding was confirmed by Nishimura (1924) and Killian (1925), and more recent reports (Montani and Perret, 1964; Sudre and Reiss, 1969; Lamisse et al., 1972; Bland et al., 1974; Controni et al., 1975) have demonstrated the value of estimating the concentration of lactic acid in CSF for distinguishing between viral and bacterial meningitis. The present study was undertaken to evaluate gas liquid chromatography for measuring CSF lactic acid as an adjunct to routine tests in the diagnosis and treatment of pyogenic meningitis.

\section{Material and methods}

\section{CEREBROSPINAL FLUID}

One hundred and forty-six consecutive specimens of CSF obtained by lumbar puncture from 135 patients between the ages of 2 weeks and 74 years admitted to the Luton and Dunstable Hospital with suspected 1163 
meningitis were examined. Cell counts, determination of protein and glucose concentrations, Gram stain, bacterial culture, and lactic acid estimations were carried out on all specimens. The fraction of the specimen for lactic acid estimation was placed in the refrigerator at $4^{\circ} \mathrm{C}$ and within a maximum interval of 12 hours the methyl derivatives of lactic acid were processed.

\section{Preparation of methyl ester derivatives}

Samples of up to $1 \mathrm{ml} \mathrm{CSF}$ in $12 \times 100 \mathrm{~mm}$ groundglass stoppered tubes (dilutions made in distilled water) were acidified with $0.5 \mathrm{ml} 50 \% \mathrm{H}_{2} \mathrm{SO}_{4} ; 2 \mathrm{ml}$ methanol were added and the mixture was incubated at $56^{\circ} \mathrm{C}$ for 30 minutes. After cooling to ambient temperature $1 \mathrm{ml}$ distilled water and $0.5 \mathrm{ml}$ chloroform were added. The sample was mixed, by means of a vortex mixer, for 15 seconds and then briefly centrifuged to break the emulsion formed. The chloroform layer was removed for injection into the gas-liquid chromatograph. Standards were prepared from lactic acid in a similar manner and the results compared with commercially available lactic acid standards (Sigma Chemicals). Analar grade reagents were used throughout.

\section{Chromatographic conditions}

To analyse the methyl esters of lactic acid, $1 \mu$ was withdrawn from the chloroform extract by a Pye Unicam S4 autojector and injected into a Pye Unicam 104 Series Chromatograph, equipped with a flame ionisation detector and fitted with a glass column ( $4 \mathrm{~mm}$ [ID] $\times 1.5 \mathrm{~m}$ ) packed with $10 \%$ polyethylene glycol adipate on celite. The gas flow rates through the detector were as follows: carrier gas, nitrogen $50 \mathrm{ml} / \mathrm{min}$, hydrogen $50 \mathrm{ml} / \mathrm{min}$, air, $500 \mathrm{ml} / \mathrm{min}$. The amplifier current was set at an attenuation of $2 \times 10^{2}\left(2 \times 10^{-10} \mathrm{~A}\right)$, and the instrument was operated isothermally at $130^{\circ} \mathrm{C}$. A chart recorder was used to produce a trace of the acid peaks detected.

\section{Reonits}

Figure 1 shows typical chromatograms obtained from a range of lactic acid standards compared with those of CSF from patients with and without meningococcal meningitis. The peaks recorded from the samples were identified as lactic acid by direct comparison of the related retention times on the column with those of the lactic acid standards. The distribution of the CSF lactic acid concentrations among the various clinical groups is shown in Figure 2. There was no significant difference between 106 patients without meningitis and the 15 patients with aseptic meningitis, the mean values for both
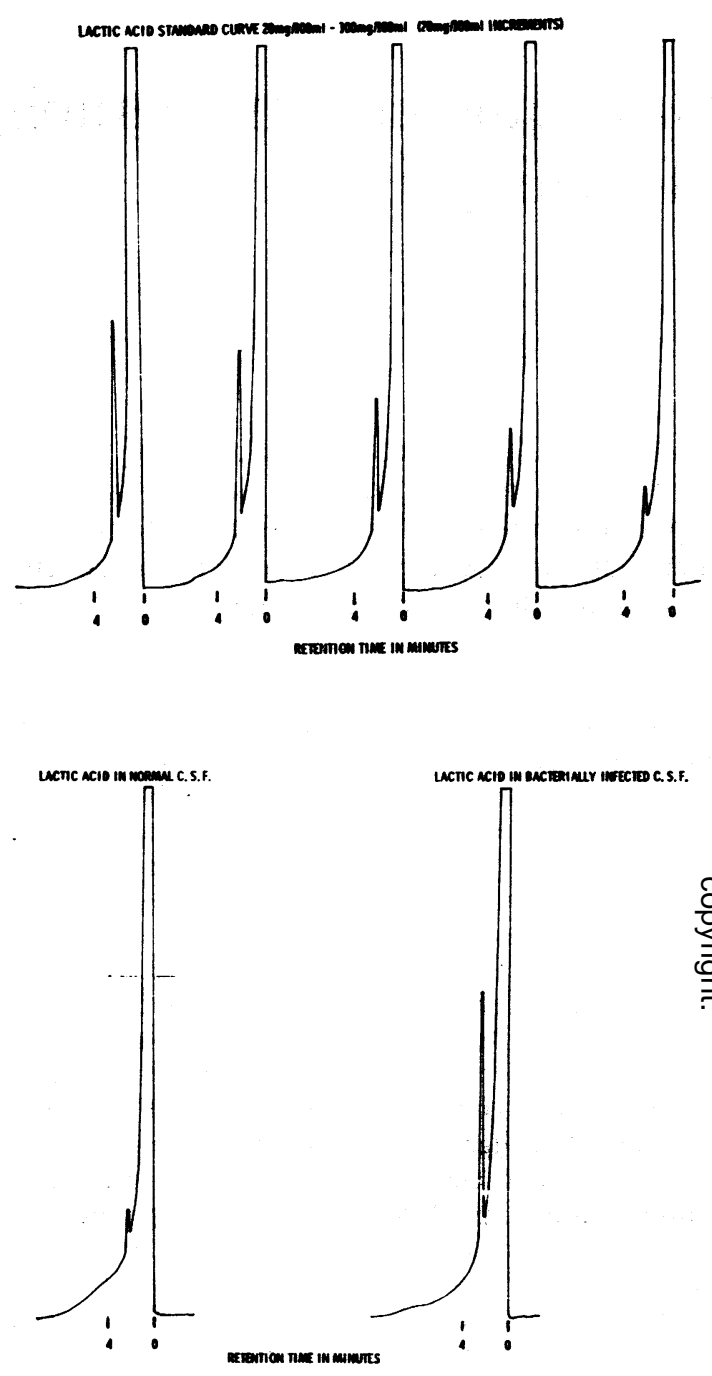

Fig. 1 Gas liquid chromatograms of lactic acid standards and of samples of cerebrospinal fuid.

Conversion: traditional units to $S I-1 \mathrm{mg} / 100 \mathrm{ml}=$ $0.9 \mathrm{mmol} / \mathrm{l}$.

groups being $22.4 \mathrm{mg} / 100 \mathrm{ml}$. In eight patients with untreated or partially treated purulent meningitis, however, the mean lactic acid concentration was raised to $121 \mathrm{mg} / 100 \mathrm{ml}$, while that for samples taken during treatment showed a significant fall to $35.5 \mathrm{mg} / 100 \mathrm{ml}$.

The number of specimens of CSF examined from patients with purulent meningitis is too small to 


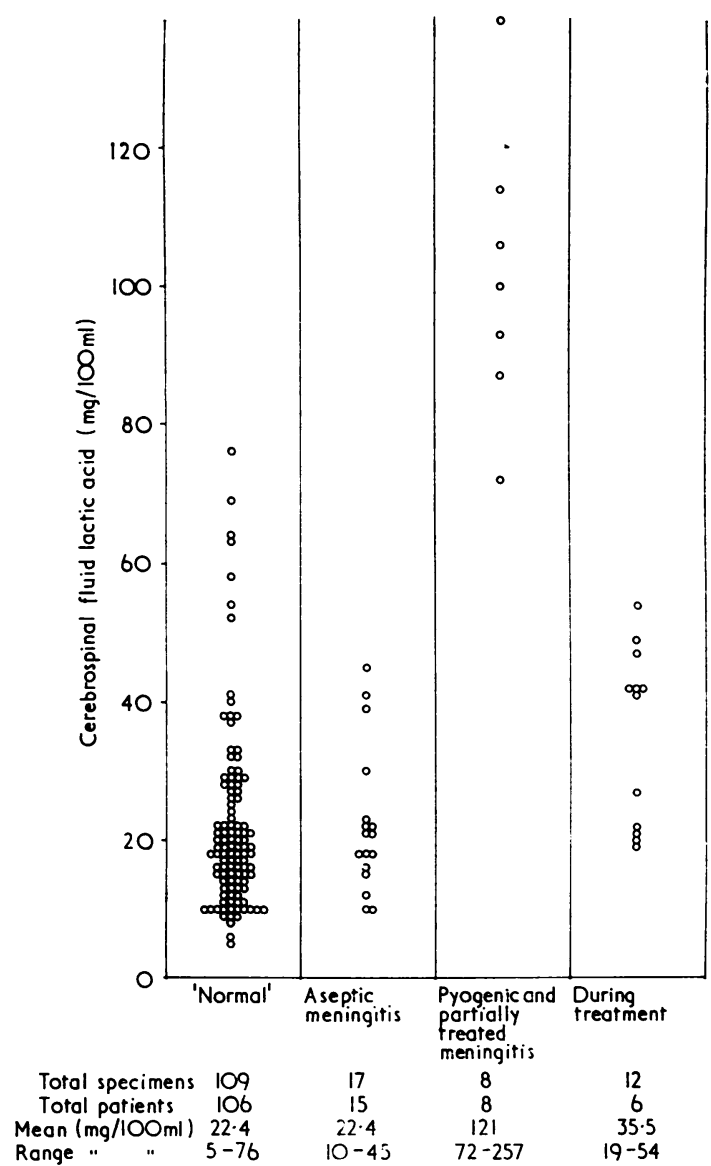

Fig. 2 Distribution of cerebrospinal fluid lactic acid values in four groups of patients.

enable valid comparisons to be made of the lactic acid concentrations associated with the different types of bacterial infection. None of the patients with meningitis died. In all eight with untreated or partially treated purulent meningitis the lactic acid concentration in the initial lumbar sample of CSF was more than $70 \mathrm{mg} / 100 \mathrm{ml}$, and in five patients was $100 \mathrm{mg} / 100 \mathrm{ml}$ or more. The highest value recorded was $257 \mathrm{mg} / 100 \mathrm{ml}$ in a 52-year-old man with group A meningococcal meningitis.

Among the 106 patients without bacterial or viral meningitis the lactic acid concentration in the CSF of seven of them was above $50 \mathrm{mg} / 100 \mathrm{ml}$. The CSF from six of these was heavily bloodstained and was not examined by gas-liquid chromatography for several hours. The other patient was a 64-year-old woman with a CSF lactic acid concentration of $69 \mathrm{mg} / 100 \mathrm{ml}$ who died soon after admission. The cause of death, confirmed post mortem, was massive cerebral infarction. It seems probable that significant amounts of lactic acid were introduced from the blood during the delay in processing, since the concentration of glucose was elevated also. The diagnosis in all these patients was subarachnoid haemorrhage. Controni et al. (1975) reported that the addition of $10 \%$ blood to a standard lactic acid solution and to samples of normal CSF had no effect on the concentration of lactic acid. Nishimura (1924), on the other hand, demonstrated that the amount of lactic acid in CSF increased on standing if the sample contained blood, and found rises of up to $100 \%$ after six hours. When this potential problem was appreciated, samples of cerebrospinal fluid were processed immediately on arrival in this laboratory. Subsequently, increased concentrations of lactic acid were not found in bloodstained samples.

Figure 3 shows the changes in concentrations of lactic acid in the CSF of five patients with purulent meningitis. In all patients there was an early reduction in the concentration to approximately $40 \mathrm{mg} / 100$

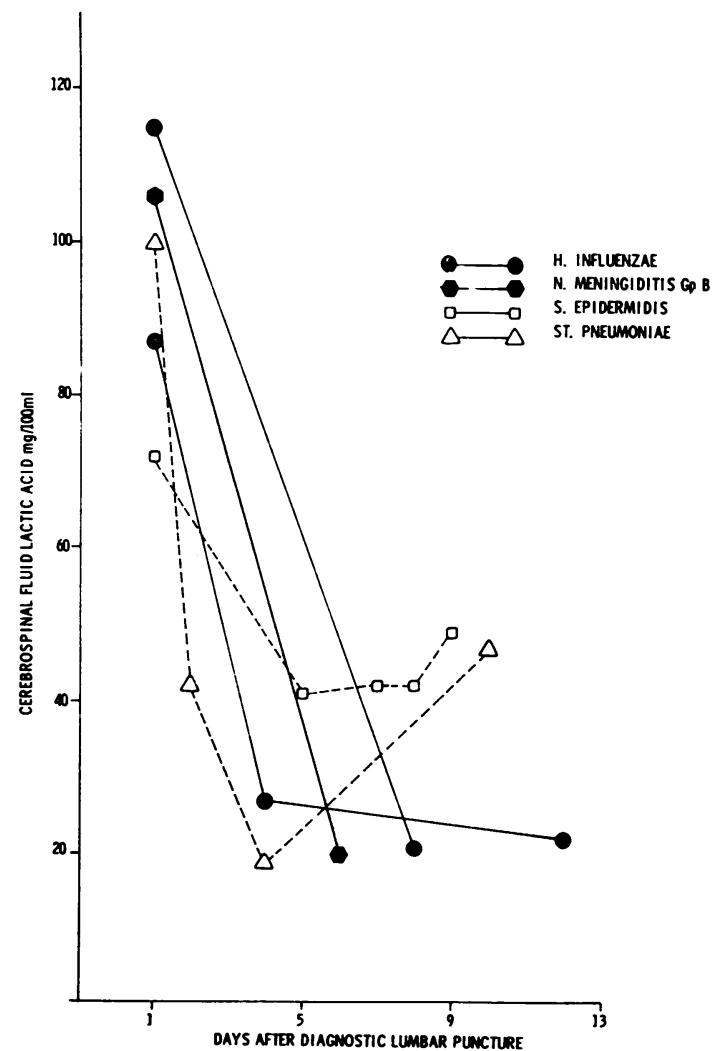

Fig. 3 Changes in cerebrospinal fluid lactic acid concentrations during treatment in five patients with bacterial meningitis. 
$\mathrm{ml}$ or less. The rate of reduction could not be accurately determined because of variation in the time of performing follow-up lumbar punctures. In the patient with pneumococcal meningitis there was initially a good clinical response to treatment and the lactic acid concentration fell from $100 \mathrm{mg} / 100 \mathrm{ml}$ to $19 \mathrm{mg} / 100 \mathrm{ml}$ on day 4 . On day 9 , however, there was clinical deterioration which indicated the development of a subdural abscess; the CSF lactic acid concentration at this time had risen to $47 \mathrm{mg} / 100$ $\mathrm{ml}$. The abscess was successfully aspirated and the patient made an uneventful recovery.

During the study samples of CSF from six patients with culture-positive meningitis were examined; in two patients the organism was Haemophilus influenzae, in two others Neisseria meningitidis (one group A, the other group B), in one Streptococcus pneumoniae, and in one Staphylococcus epidermidis. The routine CSF findings (protein, sugar, cell count. Gram stain, and culture) were unremarkable. There was considerable overlapping of these determinations among the various clinical groups of patients, so that it was impossible to demonstrate particular relationships between these values and the various clinical conditions.

\section{Discussion}

Several theories have been advanced to explain why the concentration of lactic acid in CSF is elevated in bacterial meningitis. De Sanctis et al. (1933) proposed that the white blood cells produce lactic acid as a result of glucose metabolism within the CSF, thus accounting for the finding of an increase in lactic acid and a decrease in glucose. Work by Cohn and Morse (1960), however, showed that only a small amount of lactic acid was produced by $10^{7}$ endotoxin-stimulated leucocytes, and Baltch and Osborne (1957) demonstrated that in leucocytes incubated in CSF relatively little, if any, glycolysis took place so that lactic acid could not be produced. Menkes (1969) argued that actively metabolising polymorphonuclear leucocytes contributed little to the CSF lactic acid, and this idea was further supported by findings of increased concentrations of lactic acid in the CSF of patients with tuberculous meningitis (Montani and Perret, 1964; Sudre and Reiss, 1969); in such patients few bacteria are usually found in the CSF and the cellular response is mainly a mononuclear one. It has been further postulated (Petersdorf et al., 1959) that lactic acid is produced by leucocyte-induced lysis of bacteria within the CSF. This appears unlikely in both tuberculous meningitis, when there are few bacteria, and in partially treated meningitis, when bacteria may be absent, yet in both these circumstances the lactic acid concentrations remain elevated.

The hypothesis of Kopetzky and Fishberg (1933) $\overrightarrow{\vec{F}}$ that in purulent meningitis a decrease in cerebral 0 blood supply, caused by raised intracranial pressure, 음 accounted for an increase in lactic acid has received $\frac{\bar{\sigma}}{\bar{\sigma}}$ support from the findings of Paulson et al. (1972), $\stackrel{\triangle}{\triangle}$ who demonstrated that the cerebral blood flow was decreased by about $30 \%$ in pyogenic meningitis. Plum and Posner (1967) have shown in their studies . on dogs that CSF concentrations are a reliable index of the amount of lactic acid in the brain, and the $\mathrm{pH}$ of the brain surface and of the CSF are similar. This $\overrightarrow{0}$ evidence supports the view that changes in lactic $\dot{\omega}$ acid concentration in the CSF in meningitis are a direct result of alterations in cerebral metabolism. The present study confirms the work of others $\vec{\overrightarrow{ }}$ (Montani and Perret, 1964; Sudre and Reiss, 1969; Lamisse et al., 1972; Bland et al., 1974; Controni et 윽 al., 1975) that in aseptic meningitis the CSF lactic acid concentration is essentially the same as that in CSF presumed to be normal, and that in partially treated and in untreated bacterial meningitis the concentration is significantly elevated.

The technique of gas-liquid chromatography for measuring lactic acid was found to be reliable, big the normal range was found to be broader than has. previously been reported. Samples of CSF should processed immediately on arrival in the laborator $\vec{y}$, especially if they are bloodstained, so that false high values may be avoided. By the technique described lactic acid estimations can be obtained within 40 minutes and are of particular value in recognising $\overline{\bar{\rho}}$ partially treated pyogenic meningitis when a diagnosis based on bacteriological findings may be in doubt (British Medical Journal, 1977). Furthermore, they are useful in monitoring the efficacy of treatment of pyogenic meningitis. In most patients with meningitis the diagnosis is easily confirmed. In a small number, however, the differentiation from other conditions may be difficult, either because of previous antibiotic therapy when there may be a predominantly lymphocytic response, or in those patients with viral meningitis who show an early polymorphonuclear cell reaction.

Estimations of lactic acid in the CSF provide $N$ useful additional information upon which the definitive and differential diagnosis of bacterial $\triangle$ meningitis may be based and the efficacy of therapy $\omega$ assessed. The technique is now used routinely in this laboratory.

We thank Dr A. T. Willis for useful criticism and encouragement, $\mathrm{Mr} \mathrm{J}$. Buckingham for able technical assistance, and Mrs $J$. Holt for her patience in typing the script. 


\section{References}

Baltch, A., and Osborne, W. (1957). Inquiry into causes of lowered spinal fluid sugar content: in vivo and in vitro observations. Journal of Laboratory and Clinical Medicine, 49, 882-889.

Bland, R. D., Lister, R. C., and Ries, J. P. (1974). Cerebrospinal fluid lactic acid level and $\mathrm{pH}$ in meningitis. American Journal of Diseases of Children, 128, 151-156.

British Medical Journal (1977). Leading article. Partly treated pyogenic meningitis. British Medical Journal, 1, 340.

Cohn, Z. A., and Morse, S. I. (1960). Functional and metabolic properties of polymorphonuclear leukocytes: 2 . The influence of a lipopolysaccharide endotoxin. Journal of Experimental Medicine, 111, 689-704.

Controni, G., Rodriguez, W. J., Deane, C., Ross, S., Khan, W., and Puig, J. R. (1975). Rapid diagnosis of meningitis by gas liquid chromatographic analysis of cerebrospinal fluid lactic acid. Clinical Proceedings, Children's Hospital National Medical Centre, 31, 194-201.

De Sanctis, A. G., Killian, J. A., and Garcia, T. (1933). Lactic acid of spinal fluid in meningitis. American Journal of Diseases of Children, 46, 239-249.

Greenwood, B. M., Whittle, H. C., and DominicRajkovic, O. (1971). Counter-current immunoelectrophoresis in the diagnosis of meningococcal infections. Lancet, 2, 519-521.

Jones, D. M., and Abbott, J. D. (1976). Diagnosis of pyogenic meningitis (Letter). Lancet, 2, 257.

Killian, J. A. (1925). Lactic acid of normal and pathological spinal fluids. Proceedings of the Society for Experimental Biology and Medicine, 23, 255-257.

Kopetzky, S. J., and Fishberg, E. H. (1933). Changes in distribution ratio of constituents of blood and spinal fluid in meningitis. Journal of Laboratory and Clinical Medicine, 18, 796-801.

Lamisse, F., Grenier, B., Choutet, P., Rolland, J. C., and Gautier, J. (1972). Intérêt du dosage de l'acide lactique dans le liquide rachidien pour le diagnostic des méningites purulentes. Lyon Médical, 228, 591-595.

Lancet (1976). Editorial. Diagnosis and prognosis in pyogenic meningitis. Lancet, 1, 1277-1278.

Levison, A. (1917). The hydrogen-ion concentration of cerebrospinal fluid. Journal of Infectious Diseases, 21, 556-570.

Menkes, J. H. (1969). The causes for low spinal fluid sugar in bacterial meningitis: another look. Paediatrics, 44, 1-3.

Montani, S., and Perret, C. (1964). Acidose lactique de liquide céphalo-rachidien dans les méningites bactériennes. Schweizerische medizinische Wochenschrift, 94, 1552-1557.

Nishimura, K. (1924). The lactic acid content of blood and spinal fluid. Proceedings of the Society for Experimental Biology and Medicine, 22, 322-324.

Paulson, O. B., Hansen, E. L., Kristensen, H. S., and Brodersen, P. (1972). Cerebral blood flow, cerebral metabolic rate of oxygen and C.S.F. acid-base parameters in patients with acute pyogenic meningitis and with acute encephalitis. Acta Neurologica Scandinavia, 48, (Suppl. 51), 407-408.

Petersdorf, R. G., Garcia, M., and Swarner, D. R. (1959). Mechanism of hypoglycorrhachia in experimental pneumococcal meningitis. Proceedings of the Society for Experimental Biology and Medicine, 102, 669-672.

Plum, F., and Posner, J. B. (1967). Blood and cerebrospinal fluid lactate during hyperventilation. American Journal of Physiology, 212, 864-870.

Sudre, Y., and Reiss, D. (1969). Intérêt du dosage de l'acide lactique du liquide céphalo-rachidien dans les méningites. Bordeaux Médical, 10, 2045-2059. 